EDITORIAL

\title{
Presentation of Volume 3, 1, 2021
}

\author{
José María Sarabia \\ Editor-in-Chief Spanish Journal of Statistics
}

Dear readers and dear members of the statistical community:

It is a great pleasure for me to present Volume 3, 1, corresponding to the year 2021. This volume is made up of three articles: one invited article, and two articles within the general statistics section.

The invited article is entitled "Some recent methods for analyzing high dimensional time series", whose author is Daniel Peña, winner of the first National Statistics Prize. The National Statistics Institute of Spain (INE) has awarded the National Statistics Prize to Daniel Peña Sánchez de Rivera, Emeritus Professor of Statistics and former Rector of the Carlos III University of Madrid, in recognition of his outstanding contributions, scientific work and eminent contribution to the progress of Statistics.

The article presents six recent advances in the analysis of high-dimensional time series. The first two procedures have the aim of understanding the structure of the set of series: dynamic quantiles for data visualization and clustering by dependency to split the series into homogeneous groups. The other four methods are oriented to modeling and forecasting large sets of time series by dynamic factor models (DFM). This work introduces procedures for determining the number of factors, for estimating DFM with cluster structure, for forecasting generalized dynamic factor models and for modeling matrices of time series. Some additional comments about the future evolution of the field of dependent high-dimensional data are included. It is a pleasure to have this guest article by Prof. Peña.

The next two papers are presented in the general section. The second article has the title "Misreported longitudinal data in epidemiology: Review of mixture-based advances and current challenges", whose authors are David Moriña, Amanda Fernández-Fontelo, Alejandra Cabaña, Argimiro Arratia and Pedro Puig. The problem of dealing with misinformed data is very common in a wide range of contexts. In this article, the authors consider a comprehensive review of recently proposed methods based on mixed models for longitudinal data, both correlated and uncorrelated. Several applied examples are discussed, including approximations to the burden of cases of Covid19 infection in Spain. In the same vein, different approaches are studied to deal with unreported records of human papillomavirus infections and genital warts in Catalonia.

The third paper is titled: "A note on explicit expressions for moments of order statistics", by Fredy Castellares, Artur J. Lemonte and Marcos A.C. Santos. In this article, the authors provide an alternative closed-form expression for the moments of order statistics. These formulas are applied 
to important probability distributions. The authors also consider numerical studies to demonstrate that these formulas lead to satisfactory results.

Finally, I would like to thank all the authors of this volume for choosing our journal as a means of disseminating their research. I appreciate the work of the editors and reviewers of the papers, who contribute to maintaining a high standard of scientific quality. 